\section{(A) Check for updates}

Cite this: Org. Chem. Front., 2019, 6 , 2619

Received 9th May 2019,

Accepted 9th June 2019

DOI: 10.1039/c9qo00616h

rsc.li/frontiers-organic

\title{
Ligandless nickel-catalyzed transfer hydrogenation of alkenes and alkynes using water as the hydrogen donor $\dagger$
}

\author{
Xiaoping Hu,,$^{\mathrm{a}}$ Gaonan Wang,,$^{\mathrm{a}}$ Chunxiang Qin, ${ }^{\mathrm{b}}$ Xin Xie, ${ }^{\mathrm{a}}$ Chunli Zhang, ${ }^{\mathrm{a}}$ Wei Xu ${ }^{\mathrm{a}}$ \\ and Yuanhong Liu iD *a
}

\begin{abstract}
The first general route for nickel-catalyzed transfer hydrogenation reaction of alkenes and alkynes using water as the hydrogen source has been developed. The method features the use of inexpensive and airstable nickel(II) salt as the pre-catalyst and zinc powder as a reducing agent, allowing the TH reaction to occur under mild reaction conditions with a wide substrate scope and functional group tolerance. No ligand was required for this reaction. The reaction has also been applied successfully to the reduction of nitrogen-containing heterocycles.
\end{abstract}

\section{Introduction}

Transition-metal-catalyzed hydrogenation of unsaturated $\pi$-systems is one of the most fundamental and important reactions in organic chemistry. ${ }^{1}$ These reactions usually proceed with hydrogen, a highly flammable and explosive gas. Recently, catalytic transfer hydrogenation (TH) has emerged as a promising and powerful strategy because it is operationally simple and much safer than direct hydrogenation using hydrogen gas, as no gas containment or pressure vessel is necessary. ${ }^{2}$ Compared with the $\mathrm{TH}$ reactions of polarized substrates such as aldehydes,${ }^{2}$ ketones, ${ }^{2}$ imines $^{2}$ and $\alpha, \beta$-unsaturated carbonyl compounds, ${ }^{3}$ the $\mathrm{TH}$ reactions of non-polarized unsaturated compounds such as normal alkenes or alkynes have been less developed. A variety of reagents including formic acid, ${ }^{4}$ ethanol, ${ }^{5}$ isopropanol, ${ }^{6}$ 1,4-cyclohexadiene, ${ }^{7}$ amineborane adducts ${ }^{8}$ etc. have been used as possible in situ hydrogen sources in the $\mathrm{TH}$ reactions of alkenes or alkynes. However, there are a few examples using water as the hydrogen donor. The use of water as the hydrogen donor is highly attractive since it is cheap, non-toxic, and environmentally friendly, and allows the easy isotopic labeling of the products by $\mathrm{D}_{2} \mathrm{O}$.

\footnotetext{
${ }^{a}$ State Key Laboratory of Organometallic Chemistry, Center for Excellence in Molecular Synthesis, Shanghai Institute of Organic Chemistry, University of Chinese Academy of Sciences, Chinese Academy of Sciences, 345 Lingling Lu, Shanghai 200032, People's Republic of China. E-mail: yhliu@sioc.ac.cn

${ }^{b}$ Department of Chemistry, Shanghai University, 99 Shang-Da Road, Shanghai 200444, P. R. China

$\dagger$ Electronic supplementary information (ESI) available. CCDC 1908616. For ESI and crystallographic data in CIF or other electronic format see DOI: 10.1039/ c9qo00616h

$\$$ These authors contributed equally to this work.
}

It may also offer the opportunity to disclose new reaction patterns or selectivity. However, formidable challenges remain in water-mediated reactions catalyzed by a transition metal since the resulting organometallic intermediates are generally considered to be incompatible with water. It was known that in the presence of a reductant such as zinc, nickel salts could promote the reduction of unsaturated compounds in water; however, most of these reports were restricted to $\alpha, \beta$-unsaturated carbonyls. In addition, a high catalyst loading (>30\% to excess amounts of nickel salts) was required. ${ }^{9}$ It was also reported that a combination of a stoichiometric amount of $\mathrm{NiCl}_{2} \cdot 2 \mathrm{H}_{2} \mathrm{O}$ with a large excess of lithium powder (8 equiv.) in the presence of an arene as an electron carrier was effective for the conversion of alkenes or alkynes into alkanes or alkenes. ${ }^{10}$ The hydrogen source came from the water content in the nickel salt in these cases. ${ }^{10}$ In these reactions, a high catalyst loading and a large excess of the reductant were employed. Therefore, a general and catalytic version of the Nicatalyzed reduction of common alkenes and alkynes using water has not been reported to date. Recently, Pd/Ni or Pd-catalyzed transfer hydrogenation of alkenes or alkynes using water $^{11}$ in the presence of magnesium, ${ }^{11 a} \mathrm{Cp}_{2} \mathrm{TiCl}^{11 b}$ $\mathrm{Me}_{3} \mathrm{SiSiMe}_{3},{ }^{11 c} \mathrm{~B}_{2}(\mathrm{OH})_{4},{ }^{11 d}$ or $\mathrm{B}_{2} \mathrm{Pin}_{2},{ }^{11 e}$ or Rh-catalyzed reaction in the presence of zinc ${ }^{12}$ has been reported. During our manuscript preparation, a Pd/Mn-catalyzed transfer hydrogenation of alkynes using water was reported. ${ }^{13}$ Nevertheless, the catalytic $\mathrm{TH}$ reactions by utilization of the inexpensive and earth-abundant metal catalysts are quite rare and will be highly desirable in organic chemistry. Recently, we focused our efforts on the Ni-catalyzed hydrocyanation reactions of alkynes $^{14}$ and alkenes ${ }^{15}$ using $\mathrm{Zn}(\mathrm{CN})_{2}$ as the cyanide source and water as the hydrogen source. During the course of the 


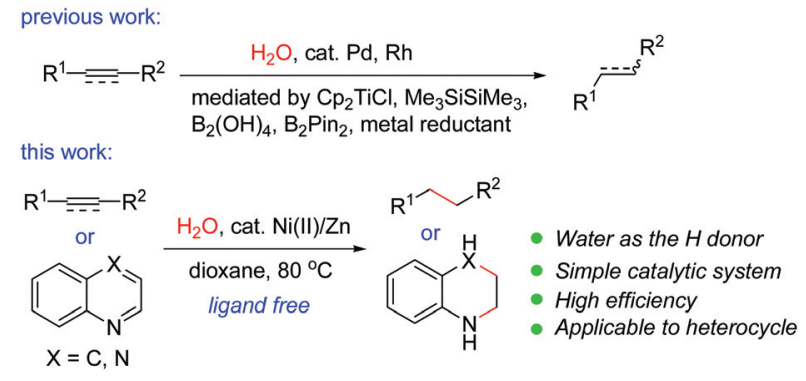

Scheme 1 Transition-metal-catalyzed transfer hydrogenation reactions.

mechanistic study, we occasionally found that alkynes could be reduced by nickel-catalyzed transfer hydrogenation in the presence of water. ${ }^{14}$ Inspired by our work, we decided to conduct an in-depth study on this topic. We now discovered that the simple combination of an air-stable nickel(II) pre-catalyst with a reducing metal under ligandless conditions is highly effective for transfer hydrogenation of alkenes and alkynes with water as the hydrogen donor (Scheme 1). The method proceeds with high generality, a wide substrate scope and good functional group tolerance. Remarkably, the reaction is also applicable to the reduction of nitrogen-containing heterocycles, which has not been achieved in nickel-catalyzed $\mathrm{TH}$ reactions using water. ${ }^{16}$

\section{Results and discussion}

We initially investigated the nickel-catalyzed transfer hydrogenation of 2-vinylnaphthalene 1a with $\mathrm{H}_{2} \mathrm{O}$. After a thorough screening of the nickel catalysts, ligands, reductants, solvents, additives etc., a highly efficient catalyst system featuring $\mathrm{NiCl}_{2} \cdot 6 \mathrm{H}_{2} \mathrm{O}(5 \mathrm{~mol} \%)$ and zinc powder (2.0 equiv.) in dioxane/ $\mathrm{H}_{2} \mathrm{O}\left(5: 1,56\right.$ equiv. $\left.\mathrm{H}_{2} \mathrm{O}\right)$ at $80^{\circ} \mathrm{C}$ was established. To our surprise, the reaction proceeded without the need for a ligand. Under these reaction conditions, 1a was reduced smoothly to afford 2-ethylnaphthalene $\mathbf{2 a}$ in $88 \%$ yield (Table 1 , entry 1 ). The use of other nickel salts such as $\mathrm{NiCl}_{2}, \mathrm{NiBr}_{2}$ or $\mathrm{NiI}_{2}$ as the catalyst was also effective for this reaction (entries 2-4). However, the use of $\mathrm{NiF}_{2}$ or $\mathrm{Ni}(\text { acac })_{2}$ led to either a trace amount of $2 \mathbf{a}$ or no conversion (entries 5 and 6). Inferior results were found when other reducing agents such as $\mathrm{Al}, \mathrm{Mn}$, and $\mathrm{Mg}$ were employed (entries 7-9). The reaction proceeded smoothly in $\mathrm{DMF} / \mathrm{H}_{2} \mathrm{O}$ and $\mathrm{THF} / \mathrm{H}_{2} \mathrm{O}$, with the formation of $2 \mathrm{a}$ in $90 \%$ and $95 \%$ yields, respectively (entries 10 and 11). Unexpectedly, the use of $\mathrm{MeCN} / \mathrm{H}_{2} \mathrm{O}$ significantly lowered the conversion, and only a trace amount of $\mathbf{2 a}$ was observed (entry 12). The amount of $\mathrm{H}_{2} \mathrm{O}$ also played an important role in this reaction, since decreasing the amount of $\mathrm{H}_{2} \mathrm{O}$ (dioxane $/ \mathrm{H}_{2} \mathrm{O}=$ $25: 1,11$ equiv. $\mathrm{H}_{2} \mathrm{O}$ ) afforded $2 \mathrm{a}$ in only $33 \%$ yield (entry 13 ). The best result was achieved by using dioxane $/ \mathrm{H}_{2} \mathrm{O}=3: 1$ (entry 14, 93 equiv. $\mathrm{H}_{2} \mathrm{O}$ ). The results indicated that a sufficient amount of water was required for this reaction. A
Table 1 Optimization of reaction conditions

\begin{tabular}{|c|c|c|c|c|c|}
\hline & 1a & $\begin{array}{r}5 \mathrm{~mol} \% \\
2.0 \text { equi } \\
\text { solve }\end{array}$ & $\begin{array}{l}\mathrm{Ni} \text { catalyst } \\
\text { iv reductant } \\
\text { ent, } 80^{\circ} \mathrm{C}\end{array}$ & & \\
\hline Entry & Catalyst & Reductant & Solvent & $\begin{array}{l}\text { Time } \\
\text { (h) }\end{array}$ & $\begin{array}{l}\text { Yield }^{a} \\
(\%)\end{array}$ \\
\hline 1 & $\mathrm{NiCl}_{2} \cdot 6 \mathrm{H}_{2} \mathrm{O}$ & $\mathrm{Zn}$ & Dioxane/ $\mathrm{H}_{2} \mathrm{O}(5 / 1)$ & 10 & 88 \\
\hline 2 & $\mathrm{NiCl}_{2}$ & $\mathrm{Zn}$ & Dioxane $/ \mathrm{H}_{2} \mathrm{O}(5 / 1)$ & 10 & 89 \\
\hline 3 & $\mathrm{NiBr}_{2}$ & $\mathrm{Zn}$ & Dioxane $/ \mathrm{H}_{2} \mathrm{O}(5 / 1)$ & 10 & 89 \\
\hline 4 & $\mathrm{NiI}_{2}$ & $\mathrm{Zn}$ & Dioxane $/ \mathrm{H}_{2} \mathrm{O}(5 / 1)$ & 10 & $79(7)$ \\
\hline 5 & $\mathrm{NiF}_{2}$ & $\mathrm{Zn}$ & Dioxane/ $\mathrm{H}_{2} \mathrm{O}(5 / 1)$ & 10 & $2(85)$ \\
\hline 6 & $\mathrm{Ni}(\mathrm{acac})_{2}$ & $\mathrm{Zn}$ & Dioxane $/ \mathrm{H}_{2} \mathrm{O}(5 / 1)$ & 10 & $-(89)$ \\
\hline 7 & $\mathrm{NiCl}_{2} \cdot 6 \mathrm{H}_{2} \mathrm{O}$ & $\mathrm{Al}$ & Dioxane $/ \mathrm{H}_{2} \mathrm{O}(5 / 1)$ & 10 & $24(68)$ \\
\hline 8 & $\mathrm{NiCl}_{2} \cdot 6 \mathrm{H}_{2} \mathrm{O}$ & $\mathrm{Mn}$ & Dioxane $/ \mathrm{H}_{2} \mathrm{O}(5 / 1)$ & 10 & $13(81)$ \\
\hline 9 & $\mathrm{NiCl}_{2} \cdot 6 \mathrm{H}_{2} \mathrm{O}$ & $\mathrm{Mg}$ & Dioxane $/ \mathrm{H}_{2} \mathrm{O}(5 / 1)$ & 10 & $-(96)$ \\
\hline 10 & $\mathrm{NiCl}_{2} \cdot 6 \mathrm{H}_{2} \mathrm{O}$ & $\mathrm{Zn}$ & $\mathrm{DMF} / \mathrm{H}_{2} \mathrm{O}(5 / 1)$ & 10 & $90(1)$ \\
\hline 11 & $\mathrm{NiCl}_{2} \cdot 6 \mathrm{H}_{2} \mathrm{O}$ & $\mathrm{Zn}$ & $\mathrm{THF} / \mathrm{H}_{2} \mathrm{O}(5 / 1)$ & 10 & 95 \\
\hline 12 & $\mathrm{NiCl}_{2} \cdot 6 \mathrm{H}_{2} \mathrm{O}$ & $\mathrm{Zn}$ & $\mathrm{CH}_{3} \mathrm{CN} / \mathrm{H}_{2} \mathrm{O}(5 / 1)$ & 10 & $1(58)$ \\
\hline 13 & $\mathrm{NiCl}_{2} \cdot 6 \mathrm{H}_{2} \mathrm{O}$ & $\mathrm{Zn}$ & Dioxane $/ \mathrm{H}_{2} \mathrm{O}(25 / 1)$ & 10 & $33(59)$ \\
\hline 14 & $\mathrm{NiCl}_{2} \cdot 6 \mathrm{H}_{2} \mathrm{O}$ & $\mathbf{Z n}$ & Dioxane $/ \mathrm{H}_{2} \mathrm{O}(3 / \mathbf{1})$ & 10 & 96 \\
\hline 15 & $\mathrm{NiCl}_{2} \cdot 6 \mathrm{H}_{2} \mathrm{O}$ & $\mathrm{Zn}$ & Dioxane/ $\mathrm{H}_{2} \mathrm{O}(3 / 1)$ & 5 & 95 \\
\hline $16^{b}$ & $\mathrm{NiCl}_{2} \cdot 6 \mathrm{H}_{2} \mathrm{O}$ & $\mathrm{Zn}$ & Dioxane $/ \mathrm{H}_{2} \mathrm{O}(3 / 1)$ & 5 & $48(48)$ \\
\hline $17^{c}$ & $\mathrm{NiCl}_{2} \cdot 6 \mathrm{H}_{2} \mathrm{O}$ & $\mathrm{Zn}$ & Dioxane $/ \mathrm{H}_{2} \mathrm{O}(3 / 1)$ & 5 & $32(63)$ \\
\hline 18 & - & $\mathrm{Zn}$ & Dioxane $/ \mathrm{H}_{2} \mathrm{O}(3 / 1)$ & 5 & $-(94)$ \\
\hline 19 & $\mathrm{NiCl}_{2} \cdot 6 \mathrm{H}_{2} \mathrm{O}$ & - & Dioxane $/ \mathrm{H}_{2} \mathrm{O}(3 / 1)$ & 5 & $-(94)$ \\
\hline
\end{tabular}

${ }^{a}$ Determined by ${ }^{1} \mathrm{H}$ NMR using 1,3,5-trimethoxybenzene as an internal standard. The yields of the unreacted 1a are shown in parentheses. ${ }^{b} 1.0$ equiv. of $\mathrm{Zn}$ was used. ${ }^{c} 50{ }^{\circ} \mathrm{C}$.

high yield of 2 a could also be observed when reducing the reaction time to $5 \mathrm{~h}$ (entry 15). Decreasing the amount of $\mathrm{Zn}$ or lowering the reaction temperature resulted in lower yields of 2a (entries 16 and 17). Control experiments indicated that both the nickel catalyst and $\mathrm{Zn}$ were essential for the reaction (entries 18 and 19).

Next, the generality of this nickel-catalyzed transfer hydrogenation protocol was investigated. The scope of aryl alkenes was first studied under the conditions shown in Table 1, entry 14. A wide range of aryl/heteroaryl alkenes were compatible for this reaction (Table 2). Aryl alkenes bearing a methyl group at the para- or ortho-position afforded high yields of $\mathbf{2 b}$ and $2 \mathbf{c}$ (86-89\%); however, a longer reaction time was needed for $2 \mathbf{c}$. The results indicated that steric hindrance has a certain influence on this reaction. Electron-donating groups such as $p$-MeO, free amino and $\mathrm{OH}$ groups as well as electron-withdrawing groups such as $p-\mathrm{Cl}, p-\mathrm{CO}_{2} \mathrm{Me}$ on the aryl rings were well tolerated, and the corresponding products of $\mathbf{2 d - 2 h}$ were obtained in $62-90 \%$ yields. Notably, a chlorine substituent was well suited in this reaction $(\mathbf{2 g})$. Special alkenes such as p-boron-, $p$-phenyl-, $p$ - $\mathrm{CH}_{2} \mathrm{OH}$-aryl alkenes and ferroceneylalkenes turned out to be efficient substrates (2i-2l). Heteroaryl alkenes such as indolyl and pyridyl alkenes reacted with water very well to form $\mathbf{2 m}$ and $\mathbf{2 n}$ in excellent yields. The reaction could be readily applied to natural product derivatives, for example estrone or formononetin derived alkenes transformed to $2 \mathbf{o}$ and $2 \mathbf{p}$ in high efficiency, while the ketone moiety in these substrates remained intact. In these cases, increasing the catalyst loading to $10 \mathrm{~mol} \%$ was required to consume the 
Table 2 Scope of the Ni-catalyzed transfer hydrogenation reactions of alkenes with $\mathrm{H}_{2} \mathrm{O}^{a}$
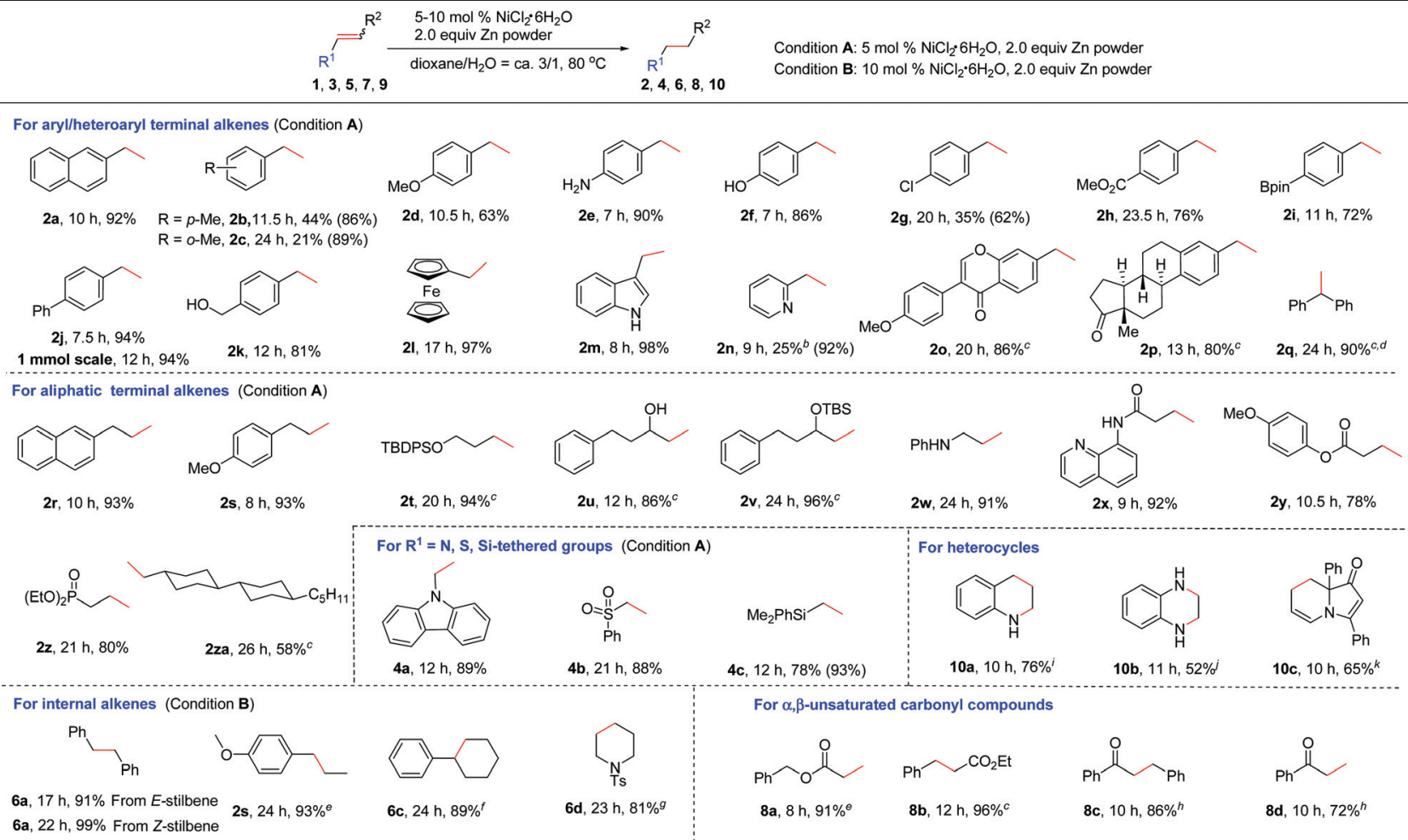

\footnotetext{
${ }^{a}$ Isolated yields. The ${ }^{1} \mathrm{H}$ NMR yields of the volatile products are shown in parentheses. ${ }^{b}$ Containing a small amount of stabilizer and solvent. ${ }^{c}$ Condition B. ${ }^{d} 2.0$ equiv. of $\mathrm{Zn}$ flakes (325 mesh) were used. ${ }^{e}$ Condition A. ${ }^{f} 3.0$ equiv. of $\mathrm{Zn}$ flakes (325 mesh) were used. ${ }^{g} 3.0$ equiv. of $\mathrm{Zn}$ powder were used. ${ }^{h} 20 \mathrm{~mol} \% \mathrm{NiCl}_{2} \cdot 6 \mathrm{H}_{2} \mathrm{O}$ and 4.0 equiv. of Al powder $(200 \mathrm{mesh})$ in dioxane/ $\mathrm{H}_{2} \mathrm{O}(5: 1) .{ }^{i} 10 \mathrm{~mol} \% \mathrm{NiCl}_{2} \cdot 6 \mathrm{H}_{2} \mathrm{O}, 3.0$ equiv. of $\mathrm{Zn}$ powder and 1.0 equiv. of $\mathrm{Et}_{3} \mathrm{~N}$ at $100{ }^{\circ} \mathrm{C}$ in dioxane $/ \mathrm{H}_{2} \mathrm{O}(5: 1) \cdot{ }^{j} 10 \mathrm{~mol} \% \mathrm{NiCl}_{2} \cdot 6 \mathrm{H}_{2} \mathrm{O}$ and 3.0 equiv. of $\mathrm{Zn}$ powder at $100{ }^{\circ} \mathrm{C}$ in dioxane/ $\mathrm{H}_{2} \mathrm{O}$ (3:1). ${ }^{k} 10 \mathrm{~mol} \% \mathrm{NiCl}_{2} \cdot 6 \mathrm{H}_{2} \mathrm{O}, 2.0$ equiv. of $\mathrm{Zn}$ powder and 1.0 equiv. of $\mathrm{Et}_{3} \mathrm{~N}$ at $100{ }^{\circ} \mathrm{C}$ in dioxane $/ \mathrm{H}_{2} \mathrm{O}(5: 1)$.
}

substrates completely. When sterically hindered 1,1-diphenylethylene 1q was employed as the substrate, a high yield of the desired 2q (ca. 94\%) was also observed; however, a small amount of the starting material (5\%) remained, which could not be separated from $\mathbf{2 q}$ by column chromatography. $\mathbf{1 q}$ was reduced completely and cleanly by replacing zinc powder by zinc flakes in the presence of $10 \mathrm{~mol} \% \mathrm{NiCl}_{2} \cdot 6 \mathrm{H}_{2} \mathrm{O}$. Possibly, zinc flakes may reduce $\mathrm{Ni}(\mathrm{II})$-salt or related nickel intermediates more efficiently than zinc powder.

Aliphatic alkenes were also easily reduced to give the corresponding alkanes in good to excellent yields. As expected, allylicnaphthalene (1r) and -benzene (1s) gave $2 \mathbf{r}$ and $2 \mathbf{s}$ in high yields. An alkyl side chain bearing an OTBDPS group was also suitable (2t). Non-protected or protected allylic alcohols transformed to $2 \mathbf{u}$ and $2 \mathbf{v}$ efficiently. In the case of $2 \mathbf{u}$, the isomerization to the corresponding ketone product was not observed. ${ }^{17}$ Allylic amine $1 \mathrm{w}$ was also confirmed to be valuable substrate for this reaction to afford the desired alkane $2 \mathrm{w}$ in $91 \%$ yield. The possible deallylation product was not observed although it was known that Ni could catalyze the $\mathrm{C}-\mathrm{N}$ bond cleavage reaction in allylic amines. ${ }^{18}$ In addition, a series of allylic substrates bearing various functional groups such as amide, ester or phosphate groups were converted to desired $2 \mathbf{x}-2 \mathbf{z}$ successfully. Alkene 1za without any functional group was reduced smoothly (2za). The reactivity of various activated alkenes was also examined, and alkenes tethered with carbazolyl, sulfonyl, and silyl groups were all compatible with this system (4a-4c).

As for internal alkenes, high conversions were achieved from both cis-(Z-5a) and trans-stilbene (E-5a), indicating that the reaction was not sensitive to the geometry of the double bond. A common naturally occurring trans-anethole worked well (2s). The reaction with tri-substituted alkenes such as 2,3,4,5-tetrahydro-1,1'-biphenyl required the use of 3.0 equiv. of zinc flakes as the reductant $(\mathbf{6 c})$. In the case of cyclic alkene $\mathbf{5 d}$, double bond migration (chain walking) to the closer position of the NTs group was observed during the reaction. A high yield of the alkane $\mathbf{6 d}$ was achieved by increasing the amount of $\mathrm{Zn}$ to 3.0 equiv. The use of an $\alpha, \beta$-unsaturated ester revealed a faster and clean reduction ( $\mathbf{8 a}$ and $\mathbf{8 b}$ ). When the reaction was applied to an $\alpha, \beta$-unsaturated ketone such as chalcone, only a low yield $(23 \%)$ of the double bond reduction product $8 \mathrm{c}$ was obtained due to the competing side reactions such as over-reduction or alkene oligomerization. To our delight, highly chemoselective reduction of the $\mathrm{C}=\mathrm{C}$ bond over the $\mathrm{C}=\mathrm{O}$ bond could be achieved by switching the reductant of $\mathrm{Zn}$ to $\mathrm{Al}$ and using $20 \mathrm{~mol} \% \mathrm{NiCl}_{2} \cdot 6 \mathrm{H}_{2} \mathrm{O}$ as the catalyst $(\mathbf{8 c}) \cdot{ }^{19}$ Under this condition, a terminal unsaturated ketone was also reduced selectively (8d). 
Reduction of heteroaromatic compounds is generally more difficult than alkenes and alkynes due to the resonance stabilization and the possible deactivation of the catalyst by either the substrate or the product. The transfer hydrogenation of heterocycles has been much less developed. ${ }^{20}$ When the reaction of quinoline was carried out in the presence of $10 \mathrm{~mol} \%$ $\mathrm{NiCl}_{2} \cdot 6 \mathrm{H}_{2} \mathrm{O} / 3.0$ equiv. $\mathrm{Zn}$, only a little product was observed, along with various byproducts. After many efforts, we found that the addition of 1.0 equiv. of $\mathrm{Et}_{3} \mathrm{~N}$ significantly improved the efficiency of this reaction to provide the desired 10a in $76 \%$ yield. The role of $\mathrm{Et}_{3} \mathrm{~N}$ is not clear yet. It might help to stabilize the catalytically active species by a weak coordination. ${ }^{21}$ Quinoxaline was reduced to $10 \mathrm{~b}$ in $52 \%$ yield, and in this case, the addition of $\mathrm{Et}_{3} \mathrm{~N}$ resulted in a complex mixture. Notably, selective reduction of one of the $\mathrm{C}=\mathrm{C}$ bonds was observed with indolizinone (10c).

The reactivity of alkynes was also evaluated (Table 3 ). In these cases, 3.0 equiv. of $\mathrm{Zn}$ were required in order to reduce alkynes completely to alkanes. Terminal arylacetylenes bearing electron-withdrawing groups or electron-rich groups were well compatible (2d-2e and 12c). Alkynes with a biphenyl (2j) or 2-naphthyl group (2a) were also smoothly reduced. Aliphatic terminal alkynes bearing various functional groups such as ether, amide, $\mathrm{OH}$, or phenyl groups and silyl alkyne worked well to afford the corresponding $\mathbf{1 2 f}-\mathbf{1 2} \mathbf{j}$ in moderate to good yields. Particularly, propargyl amide (12g) and tertiary propargyl alcohol (12h) were tolerable. Bis(aryl)alkynes such as diphenylacetylene were cleanly reduced (6a). Reduction of phenyl, alkyl-acetylene and dialkyl acetylene also proceeded smoothly (12l and $\mathbf{1 2 m})$. In alkyne reductions, we could observe the formation of alkenes at the early stage of the reaction in some cases. Thus, the reaction proceeds via generation of an alkene intermediate which undergoes further reduction to deliver the alkane product.

In order to understand the mechanism, various control experiments were performed. Reduction of diphenylacetylene with $\mathrm{D}_{2} \mathrm{O}$ using $\mathrm{NiCl}_{2}$ as the catalyst afforded the deuterated

Table 3 Scope of alkynes ${ }^{a}$

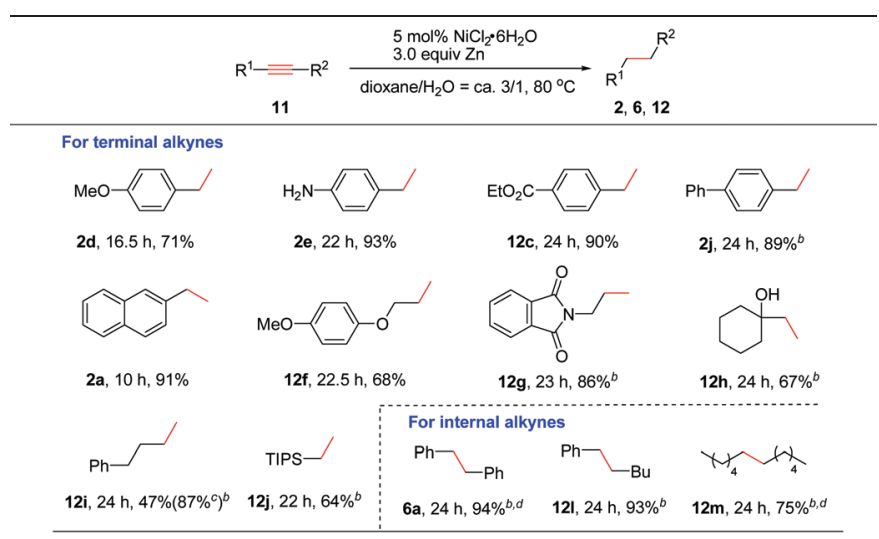

${ }^{a}$ Isolated yields. ${ }^{b} 10 \mathrm{~mol} \% \mathrm{NiCl}_{2} \cdot 6 \mathrm{H}_{2} \mathrm{O}$ was used. ${ }^{c}{ }^{1} \mathrm{H}$ NMR yield using 1,3,5-trimethoxybenzene as an internal standard. ${ }^{d} \mathrm{Zn}$ flakes (325 mesh) were used.

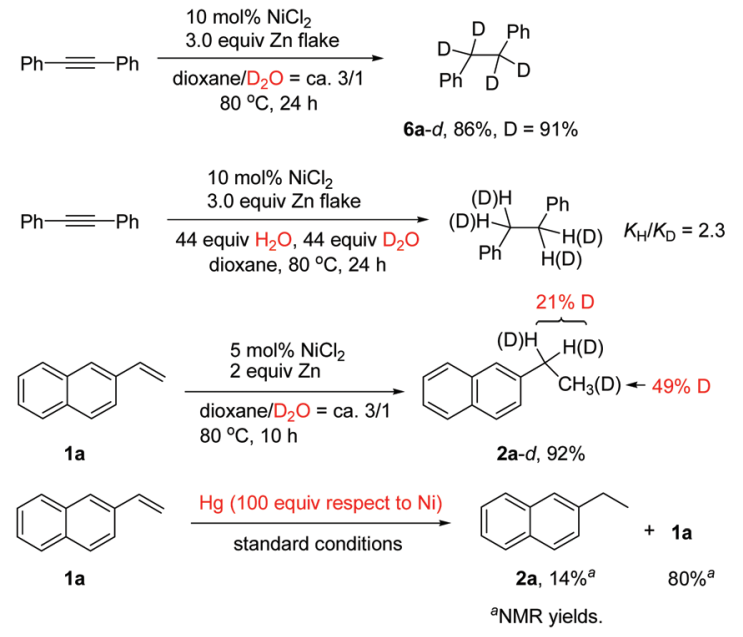

(1)

Scheme 2 Control experiments.

product $6 \mathrm{a}-\mathrm{d}$ in $86 \%$ yield with high deuterium incorporation (Scheme 2, eqn (1)), indicating that water acts as the hydrogen source for this reaction. A kinetic isotope effect was examined by employing an equimolar mixture of $\mathrm{H}_{2} \mathrm{O}$ and $\mathrm{D}_{2} \mathrm{O}$ as the $\mathrm{H}$ and $\mathrm{D}$ donor, which revealed a primary kinetic isotope effect $\left(k_{\mathrm{H}} / k_{\mathrm{D}}=2.3\right)$. Parallel experiments indicated that $k_{\mathrm{H}} / k_{\mathrm{D}}=3 .^{22}$ The results imply that the $\mathrm{O}-\mathrm{H}$ bond cleavage of $\mathrm{H}_{2} \mathrm{O}$ is likely involved in the rate-determining step (Scheme 2, eqn (2)). ${ }^{11 d}$ In the reaction of alkene 1a with $\mathrm{D}_{2} \mathrm{O}$, deuterium was found in both the benzylic position and methyl group (Scheme 2, eqn (3)). The results indicated that a $\mathrm{Ni}-\mathrm{H}$ species might be generated, and addition of $\mathrm{Ni}-\mathrm{H}$ to the alkene is reversible under the reaction conditions. The yield of the product $\mathbf{2 a}$ was decreased significantly upon addition of mercury (Scheme 2, eqn (4)), indicating that a heterogeneous system might be involved in this transfer hydrogenation reaction. We also noted that hydrogen gas evolution could be detected at $80{ }^{\circ} \mathrm{C}$ regardless of the presence or absence of a substrate. ${ }^{9 d}$ The detailed reaction mechanism was not clear yet at the moment. Possibly, a $\mathrm{Ni}(0)$ species is first generated through reduction of the Ni(II) salt by $\mathrm{Zn}$. This is followed by a catalytic hydrogenation process involving reduction of the substrate on the nickel surface with the absorbed $\mathrm{H}_{2}$ gas. ${ }^{9 d, 23}$

\section{Conclusions}

In summary, we have developed the first general and operationally simple protocol for nickel-catalyzed transfer hydrogenation reaction of alkenes and alkynes using water as the hydrogen source. The method features the use of inexpensive and air-stable nickel(II) salt as the pre-catalyst and zinc as a reducing agent, allowing the TH reaction to occur under mild reaction conditions with a wide substrate scope and functional group tolerance. The method does not require the use of a ligand. The reaction has also been applied successfully to the 
reduction of nitrogen-containing heterocycles. Further investigations on the detailed reaction mechanism and application of this chemistry are in progress.

\section{Conflicts of interest}

There are no conflicts to declare.

\section{Acknowledgements}

We thank the National Key R\&D Program of China (2016YFA0202900), the National Natural Science Foundation of China (21772217), the Strategic Priority Research Program of the Chinese Academy of Sciences (XDB20000000), the Science and Technology Commission of Shanghai Municipality (18XD1405000) and the Shanghai Institute of Organic Chemistry (sioczz201807) for financial support.

\section{Notes and references}

1 (a) The Handbook of Homogeneous Hydrogenation, ed. J. G. de Vries and C. J. Elsevier, Wiley-VCH, Weinheim, 2007; (b) Modern Reduction Methods, ed. P. G. Andersson and I. J. Munslow, Wiley-VCH Verlag GmbH \& Co. KGaA, Weinheim, 2008.

2 For reviews, see: (a) C. Wang, X. Wu and J. Xiao, Chem. Asian J., 2008, 3, 1750; (b) D. Wang and D. Astruc, Chem. Rev., 2015, 115, 6621; (c) S. Werkmeister, J. Neumann, K. Junge and M. Beller, Chem. - Eur. J., 2015, 21, 12226.

3 For selected papers, see: (a) A. D. Kosal and B. L. Ashfeld, Org. Lett., 2010, 12, 44; (b) J.-Y. Shang, F. Li, X.-F. Bai, J.-X. Jiang, K.-F. Yang, G.-Q. Lai and L.-W. Xu, Eur. J. Org. Chem., 2012, 2809; (c) B. Ding, Z. Zhang, Y. Liu, M. Sugiya, T. Imamoto and W. Zhang, Org. Lett., 2013, 15, 3690.

4 (a) J. M. Brunel, Tetrahedron, 2007, 63, 3899; (b) J. Broggi, V. Jurčík, O. Songis, A. Poater, L. Cavallo, A. M. Z. Slawin and C. S. J. Cazin, J. Am. Chem. Soc., 2013, 135, 4588.

5 Y. Wang, Z. Huang, X. Leng, H. Zhu, G. Liu and Z. Huang, J. Am. Chem. Soc., 2018, 140, 4417.

6 (a) S. Horn and M. Albrecht, Chem. Commun., 2011, 47, 8802; (b) G. Zhang, Z. Yin and J. Tan, RSC Adv., 2016, 6, 22419; (c) Z. Mazloomi, R. Pretorius, O. Pàmies, M. Albrecht and M. Diéguez, Inorg. Chem., 2017, 56, 11282.

7 J. F. Quinn, D. A. Razzano, K. C. Golden and B. T. Gregg, Tetrahedron Lett., 2008, 49, 6137.

8 H. Dong and H. Berke, J. Organomet. Chem., 2011, 696, 1803.

9 (a) K. Sakai, M. Ishige, H. Kono, I. Motoyama, K. Watanabe and K. Hata, Bull. Chem. Soc. Jpn., 1968, 41, 1902; (b) C. Petrier and J.-L. Luche, Tetrahedron Lett., 1987, 28, 2347; (c) C. Petrier and J.-L. Luche, Tetrahedron Lett., 1987, 28, 2351; (d) C. Petrier, J.-L. Luche, S. Lavaitte and C. Morat, J. Org. Chem., 1989, 54, 5313; (e) M. J. Hazarika and N. C. Barua, Tetrahedron Lett., 1989, 30, 6567; (f) C. Pétrier, S. Lavaitte and C. Morat, J. Org. Chem., 1990, 55, 1664; $(g)$ H. IIikti, T. Benabdallah, K. Bentayeb, A. A. Othman and Z. Derriche, S. Afr. J. Chem., 2008, 61, 31; (h) Y.-G. Chen, B. Shuai, C. Ma, X.-J. Zhang, P. Fang and T.-S. Mei, Org. Lett., 2017, 19, 2969.

10 (a) F. Alonso and M. Yus, Tetrahedron Lett., 1996, 37, 6925;

(b) F. Alonso and M. Yus, Tetrahedron Lett., 1997, 38, 149;

(c) F. Alonso and M. Yus, Tetrahedron Lett., 1998, 54, 1921. For related $\mathrm{FeCl}_{2} \cdot 4 \mathrm{H}_{2} \mathrm{O} / \mathrm{Li} /$ arene mediated reduction, see: (d) Y. Moglie, F. Alonso, C. Vitale, M. Yus and G. Radivoy, Tetrahedron, 2006, 62, 2812.

11 (a) O. Muhammad, S. U. Sonavane, Y. Sasson and M. Chidambaram, Catal. Lett., 2008, 125, 46; (b) A. G. Campaña, R. E. Estévez, N. Fuentes, R. Robles, J. M. Cuerva, E. Buñuel, D. Cárdenas and J. E. Oltra, Org. Lett., 2007, 9, 2195; (c) E. Shirakawa, H. Otsuka and T. Hayashi, Chem. Commun., 2005, 5885; (d) S. P. Cummings, T.-N. Le, G. E. Fernandez, L. G. Quiambao and B. J. Stokes, J. Am. Chem. Soc., 2016, 138, 6107; (e) D. P. Ojha, K. Gadde and K. R. Prabhu, Org. Lett., 2016, 18, 5062.

12 T. Sato, S. Watanabe, H. Kiuchi, S. Oi and Y. Inoue, Tetrahedron Lett., 2006, 47, 7703.

13 C.-Q. Zhao, Y.-G. Chen, H. Qiu, L. Wei, P. Fang and T.-S. Mei, Org. Lett., 2019, 21, 1412.

14 X. Zhang, X. Xie and Y. Liu, J. Am. Chem. Soc., 2018, 140, 7385.

15 G. Wang, X. Xie, W. Xu and Y. Liu, Org. Chem. Front., 2019, 6, 2037.

16 For reduction of nitrogen-containing heterocycles by $\mathrm{NiCl}_{2} \cdot 2 \mathrm{H}_{2} \mathrm{O}$ - $\mathrm{Li}$-arene combination with a stoichiometric amount of $\mathrm{Ni}$ salt and a large excess of lithium powder, see: (a) G. Radivoy, F. Alonso and M. Yus, Tetrahedron, 1999, 55, 14479. For other metal-catalyzed $\mathrm{TH}$ reactions using water, see: $(b)$ C. Wang, C. Li, X. Wu, A. Pettman and J. Xiao, Angew. Chem., Int. Ed., 2009, 48, 6524; (c) D. Talwar, H. Y. Li, E. Durham and J. Xiao, Chem. - Eur. J., 2015, 21, 5370.

17 R. Uma, C. Crévisy and R. Grée, Chem. Rev., 2003, 103, 27.

18 T. Taniguchi and K. Ogasawara, Tetrahedron Lett., 1998, 39, 4679.

$19 \mathrm{An} \mathrm{Al} / \mathrm{NiCl}_{2} \cdot 6 \mathrm{H}_{2} \mathrm{O}$ system with high loading (10 equiv.) for both metals has been used to reduce $\alpha, \beta$-unsaturated compounds, see ref. $9 e$.

20 For other metal-catalyzed $\mathrm{TH}$ reactions using water or alcohol as the hydrogen source, see: (a) V. H. Mai and G. I. Nikonov, Organometallics, 2016, 35, 943; (b) Ref. 16b and $c(c)$ Ref. 5 .

21 J. Yu and J. B. Spencer, Chem. Commun., 1998, 1103.

22 See the ESI. $\dagger$

23 We found that in several cases, the yields of the desired products were influenced by the volume of the reaction vessel. The yield of the product was decreased by using a larger tube. The results indicated that the $\mathrm{H}_{2}$ gas concentration may have an important impact on the reaction. 